\title{
Histopathological Review of Male Breast Cancer Cases
}

\author{
Emel Ebru Pala ${ }^{1}$, Zubeyde Yildirim $^{1}$, Ulku Kucuk $^{1}$, Ebru Cakir $^{1}$, Nilay Senkorkmaz ${ }^{2}$, Umit Bayol $^{1}$
}

\begin{abstract}
Objective: Male breast cancer (MBC) accounts for less than $1 \%$ of all breast cancer diagnoses and all cancer cases in men.

Methods: We included $33 \mathrm{MBC}$ cases and analyzed histopathological features and survival data.

Results: The mean age was 63.5 , mean tumor diameter was $3 \mathrm{~cm}$. Central quadrants $(69.2 \%)$ was most common localization, invasive ductal carcinoma $(75.8 \%)$ was most common histological subtype. Most of the cases $(78.6 \%)$ were grade 2 . Nipple involvement was noted in 9 , tumor necrosis in 9 , perineural invasion in 15 , dermal lymphatic emboli in 10 cases. Nearly half of the cases $(45.5 \%)$ showed lymph node metastasis. There was statistically significant relation between lymph node metastasis and stromal lymphocyte response, tumor necrosis $(\mathrm{p}=0.008, \mathrm{p}=0.013)$ also between grade and dermal lymphatic emboli $(\mathrm{p}=0.04)$. Non-tumoral parenchymal findings were columnar cell lesions (CCL), (n: 5) and gynaecomastia (n: 3). Majority of the cases showed estrogen receptor $(90.9 \%)$ and progesterone receptor $(77.2 \%)$ positivity. Overall survival analysis showed significant results between grade $(p=0.008)$, lymph node metastasis $(p=0.03)$, dermal lymphatic tumor emboli $(\mathrm{p}=0.02)$, nipple involvement $(\mathrm{p}=0.02)$ and survival.

Conclusions: Our results showed good correlation with literature data in terms of histopathological features and prognostic factors. Confidential data about etiological and prognostic factors will be collected through these reports showing institutional experiences. The significance of CCL in MBC etiology, the impact of intratumoral stromal lymphocyte response, hormone receptor-HER2 status on survival should be clarified in larger series.
\end{abstract}

Keywords: Male breast cancer, Prognosis, Histopathology

Introduction

Male breast cancer (MBC) accounts for less than $1 \%$ of all breast cancers diagnoses and all cancer cases in men [1]. Incidence rate is higher in North America, Europe and Africa [2]. The mean age at diagnosis is 67 which is higher than the mean age reported in woman [3]. Etiopathological factors of $\mathrm{MBC}$ are genetic predisposition (BRCA2 mutation), estrogen-testosterone ratio alterations (Klinefelter syndrome, obesity, liver cirrhosis, exogenous estrogen therapy), radiation exposure and occupational risks $[1,4,5]$.

Most common histopathological subtype is invasive ductal carcinoma $(85-90 \%)[4,6]$. The vast majority $(65-90 \%)$ of $\mathrm{MBC}$ are estrogen and progesterone receptor positive [4,6]. Axillary lymph node metastasis is observed in nearly half of MBC cases [7].

The current approaches in MBC treatment are surgery (simple-modified radical mastectomy, sentinel node biopsy), hormonotherapy, radiotherapy, chemotherapy [6].
Our aim was to analyze the demographic and clinical characteristics of MBC patients and predictive factors impact on overall survival.

\section{Material and Methods}

We included 33 MBC cases diagnosed between 2000-2014 in Tepecik Training and Research Hospital. We reviewed hematoxylin-eosin stained sections in terms of histological tumor type, grade, necrosis, perineural invasion, dermal lymphatic invasion, DCIS component, nipple involvement, lymph node metastasis, stromal lymphocyte response, non-tumoral parenchymal features. We also searched pathology reports for tumor diameter, localization, hormone receptor, HER2 status and archive records for survival data.

\section{Statistical Analysis}

Statistical analyses were performed by using SPSS software version 16. Overall survival rates were 
estimated by Kaplan-Meier. Pearson's chi-square test and Mann Whitney U test were used to analyze the data, as appropriate. The results were considered to be statistically significant when $\mathrm{p}<$ 0.05

\section{Results}

The mean age was $63.5(\min : 48, \max : 90)$, mean diameter was $3 \mathrm{~cm}(\min : 1, \max : 5 \mathrm{~cm})$. We could achieve follow up/survival data of 22 cases of which 14 alive and 8 died. Mean follow up period was 55.8 months (min:3, max:155). Central quadrant $(69.2 \%)$ was the most common localization. Histopathological subtype was invasive ductal carcinoma (IDC) in 25 cases (75.8\%), papillary carcinoma in 3 cases $(9 \%)$, ductal carcinoma in situ (DCIS) in 5 cases $(15.2 \%)$. Of the 25 IDC cases, 5 exhibited in situ component. Twenty two cases were grade $2(78.6 \%)$, six cases were grade $3(21.4 \%)$. Lymph node excision was performed in 22 cases and 10 cases (45.5\%) showed lymph node metastasis. Six cases had distant metastasis. Nipple involvement was noted in 9 cases, of which 7 located in central quadrant, 8 were IDC, 1 was pure DCIS and 1 had in situ component in addition to invasive component. Tumor necrosis was seen in 9 cases $(27.3 \%)$, perineural invasion in 15 cases $(45,5 \%)$, tumor emboli in dermal lymphatics in 10 cases $(30.3 \%)$. There was a statistically significant relation between presence of tumor emboli in dermal lymphatic and central quadrant localization $(\mathrm{p}=$ 0.03 ). We noted stromal lymphocyte response in tumoral areas in six cases of which five showed lymph node metastasis (Figure 1). Correlation between the presence of stromal lymphocyte and lymph node metastasis was statistically significant $(p=0.008)$. There was also statistically significant relation between lymph node metastasis and tumor necrosis $(p=0.013)$ also between grade and dermal lymphatic tumor emboli ( $\mathrm{p}=0.04)$.

Non-tumoral parenchymal findings were columnar cell hyperplasia (n:5) (Figure 2) and gynaecomastia (n:3).

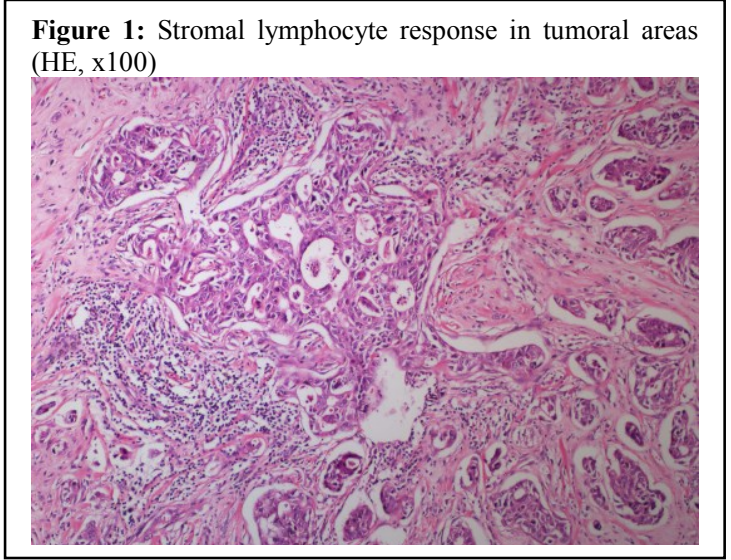

Hormone receptor and HER2 status were documented in 22 cases. Estrogen receptor was positive in $20(90.9 \%)$, progesterone receptor in 17 (77.2\%) and HER2 in $3(13.6 \%)$ cases.

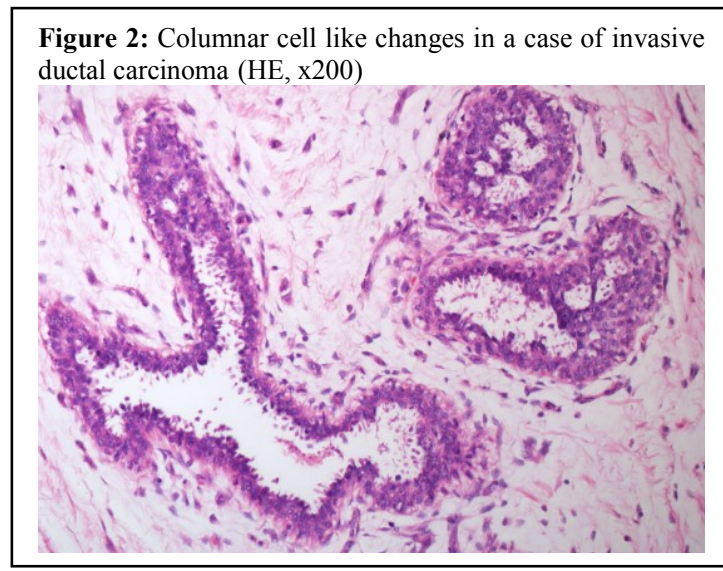

Overall survival analysis showed significant results between grade $(\mathrm{p}=0.008)$ (Figure $3)$, lymph node metastasis $(p=0.03)$, dermal lymphatic tumor emboli $(\mathrm{p}=0.02)$, nipple involvement $(\mathrm{p}=0.02)$ and survival.

\section{Discussion}

Grujicic et al and Bruce et al reported IDC as most common subtype because male breast normally consist of only ducts $[8,9]$. Lobular tissue is present only in case of increased estrogen exposure [4]. Papillary carcinoma is more frequent in male $(2-4 \%)$ than women [4]. In our study two most common subtypes were IDC $(75.8 \%)$ and papillary carcinoma $(9 \%)$.

DCIS accounts nearly $10 \%$ of MBCs [10]. In our study pure DCIS was seen in $15.1 \%$ of the cases. Lanitis et al reported accompanying in situ component in $78.6 \%$ of invasive cancer cases though it was $20 \%$ in our serial.

Etiology of MBC is still not clear. Defined risk factors are family history and increased estrogen levels. We could not achieve family history in our cases. But we search for proliferative lesions around tumoral areas. Columnar cell lesions (CCL) are well known precursors of low grade breast neoplasia in female though their role in $\mathrm{MBC}$ has not been established. Also the association between gynaecomastia and male breast cancer risk is not clear [1]. Ni et al investigated columnar cell lesions in 71 male patients who underwent breast surgery for benign and malignant lesions. They noted columnar cell like changes in 39 patients. The incidence of CCL was similar in malignant and benign lesions [11]. Another recent study found no CCL around invasive cancer, gynaecomastia and normal breast tissue [12]. 


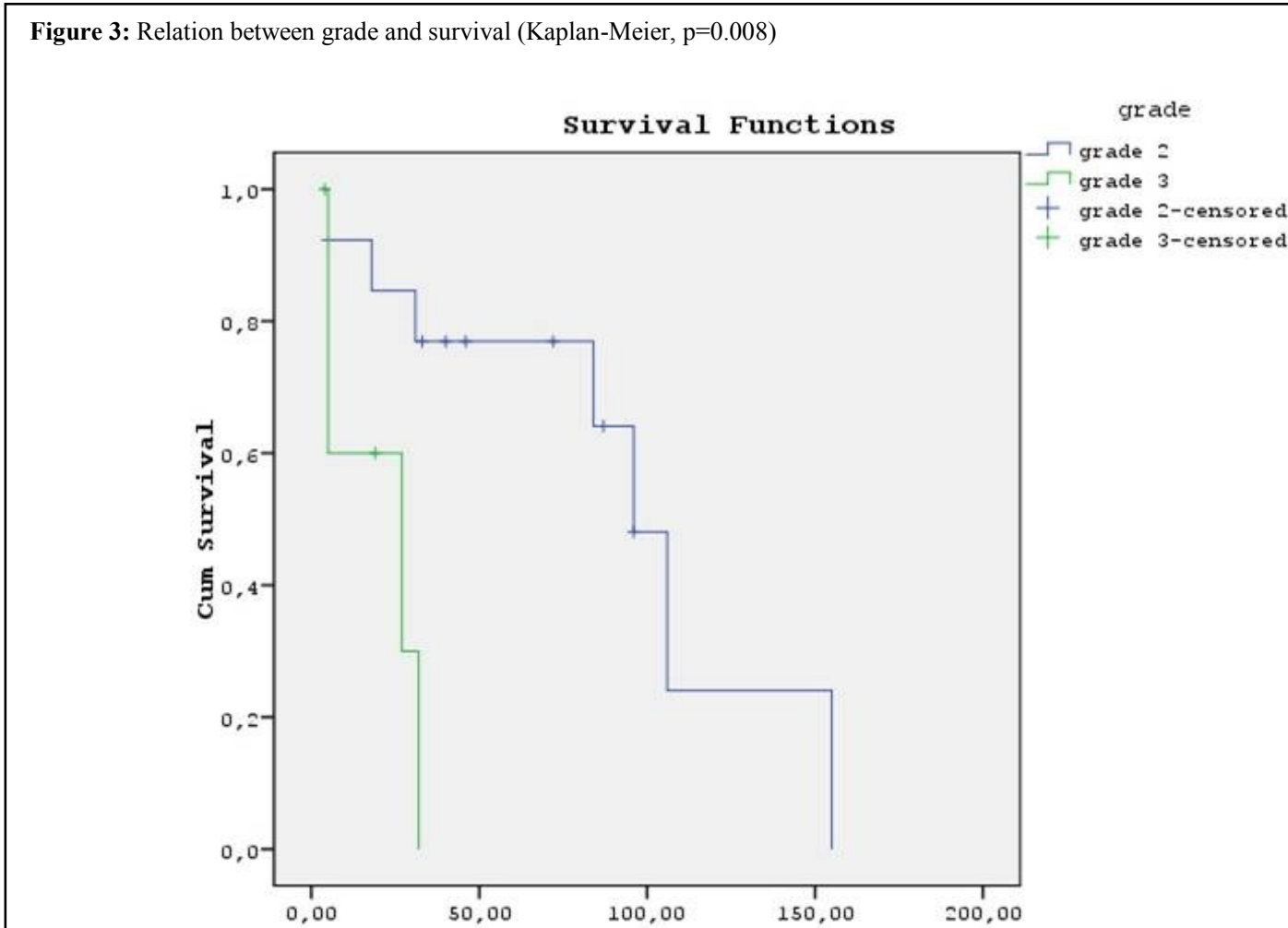

In our serial three breasts carcinoma cases had accompanying gynaecomastia, five had CCL without atypia. The incidence and the role of CCL in $\mathrm{MBC}$ carcinogenesis should further analyzed in larger series.

As the majority of MBC cases are hormone receptor positive, hormone treatment is indicated in the vast majority of the patients. But the impact of hormone therapy on survival is still controversial. No strong evidence was reported between ER status and prognosis of MBC [13,14]. We could not find significant relation between ER positivity and overall survival $(\mathrm{p}=0.52)$. Besides mean survival time for ER $(+)(62.8 \pm 10.6)$ cases was lower than ER (-) $(90 \pm 4.2)$ cases. But we have no data if hormone receptor positive cases achieve hormonotherapy or not.

There are conflicting data about tumorinfiltrating lymphocytes and breast cancer prognosis. Loi et al found that extensive lymphocytic infiltration in node positive, ER/HER2 negative breast cancer is associated with excellent prognosis [15]. Rathore et al reported stromal CD3 positive TILs were significantly associated with positive lymph node status [16]. In our study we examined stromal lymphocyte infiltration in tumoral areas and half of the cases exhibiting extensive stromal lymphocyte showed lymph node metastasis. Clinical stage is identified as important prognostic factor in $\mathrm{MBC}$ in many studies. The prognosis depends on tumor size, grade, lymph node status $[13,17,18]$. The overall 5 - year survival in case of lymph node metastasis is $57 \%$, whereas it is $85 \%$ in non-metastatic cases [18]. Age, size, grade, lymph node metastasis and steroid receptor status are defined as independent prognostic factors for $\mathrm{MBC}$ survival [8]. Bergmann et al found that metastasis at diagnosis, older age, higher tumor stage and smoking status are independent factors associated with risk of death [8]. Grujicic et al showed $100 \%$ overall survival for tumors $\leq 2 \mathrm{~cm}$, $38 \%$ for tumors $>5 \mathrm{~cm}$ [8]. According to our study the relation between tumor diameter, grade, nipple involvement, lymph node metastasis, dermal lymphatic emboli and survival were statistically significant.

\section{Conclusion}

Our results showed good correlation with literature data in terms of histopathological features and prognostic factors. Confidential data about etiological and prognostic factors will be collected through these reports showing institutional experiences. The significance of $\mathrm{CCL}$ in $\mathrm{MBC}$ etiology, the impact of intratumoral stromal lymphocyte response on prognosis, also hormone receptor and HER2 status on survival should be clarified in larger series.

Financial Support: This research received no specific grant from any funding agency, commercial or not-for-profit sectors 
Conflict of Interest: The authors declared that they had no conflicts of interest.

\section{References}

[1] Sasco AJ, Lowenfels AB, Pasker-de Jong P. Review article: epidemiology of male breast cancer. A metaanalysis of published case-control studies and discussion of selected aetiological factors. International journal of cancer Journal international du cancer. 1993;53(4):53849.

[2] Weiss JR, Moysich KB, Swede H. Epidemiology of male breast cancer. Cancer epidemiology, biomarkers \& prevention : a publication of the American Association for Cancer Research, cosponsored by the American Society of Preventive Oncology. 2005;14(1):20-6.

[3] Giordano SH, Cohen DS, Buzdar AU, Perkins G, Hortobagyi GN. Breast carcinoma in men: a populationbased study. Cancer. 2004;101(1):51-7.

[4] Fentiman IS, Fourquet A, Hortobagyi GN. Male breast cancer. Lancet. 2006;367(9510):595-604.

[5] Ottini L, Palli D, Rizzo S, Federico M, Bazan V, Russo A. Male breast cancer. Critical reviews in oncology/hematology. 2010;73(2):141-55.

[6] Contractor KB, Kaur K, Rodrigues GS, Kulkarni DM, Singhal H. Male breast cancer: is the scenario changing. World journal of surgical oncology. 2008;6:58.

[7] Czene K, Bergqvist J, Hall P, Bergh J. How to treat male breast cancer. Breast. 2007;16 Suppl 2:S147-54.

[8] Sipetic-Grujicic SB, Murtezani ZH, NeskovicKonstatinovic ZB, Marinkovic JM, Kovcin VN, Andric $\mathrm{ZG}$, et al. Multivariate analysis of prognostic factors in male breast cancer in Serbia. Asian Pacific journal of cancer prevention : APJCP. 2014;15(7):3233-8.

[9] Bruce DM, Heys SD, Payne S, Miller ID, Eremin O. Male breast cancer: clinico-pathological features, immunocytochemical characteristics and prognosis. European journal of surgical oncology : the journal of the European Society of Surgical Oncology and the British Association of Surgical Oncology. 1996;22(1):42-6.
[10] Agrawal A, Ayantunde AA, Rampaul R, Robertson JF. Male breast cancer: a review of clinical management. Breast cancer research and treatment. 2007;103(1):11-21.

[11] Ni YB, Mujtaba S, Shao MM, Lacambra M, Tsang JY, Chan SK, et al. Columnar cell-like changes in the male breast. Journal of clinical pathology. 2014;67(1):45-8.

[12] Verschuur-Maes AH, Kornegoor R, de Bruin PC, Oudejans JJ, van Diest PJ. Do columnar cell lesions exist in the male breast? Histopathology. 2014;64(6):818-25

[13] Nahleh Z, Girnius S. Male breast cancer: a gender issue. Nature clinical practice Oncology. 2006;3(8):428-37.

[14] Hill TD, Khamis HJ, Tyczynski JE, Berkel HJ. Comparison of male and female breast cancer incidence trends, tumor characteristics, and survival. Annals of epidemiology. 2005;15(10):773-80.

[15] Loi S, Sirtaine N, Piette F, Salgado R, Viale G, Van Eenoo F, et al. Prognostic and predictive value of tumorinfiltrating lymphocytes in a phase III randomized adjuvant breast cancer trial in node-positive breast cancer comparing the addition of docetaxel to doxorubicin with doxorubicin-based chemotherapy: BIG 02-98. Journal of clinical oncology : official journal of the American Society of Clinical Oncology. 2013;31(7):860-7.

[16] Rathore AS, Kumar S, Konwar R, Srivastava AN, Makker A, Goel MM. Presence of CD3+ tumor infiltrating lymphocytes is significantly associated with good prognosis in infiltrating ductal carcinoma of breast. Indian journal of cancer. 2013;50(3):239-44.

[17] Giordano SH. A review of the diagnosis and management of male breast cancer. The oncologist. 2005;10(7):471-9

[18] Meguerditchian AN, Falardeau M, Martin G. Male breast carcinoma. Canadian journal of surgery Journal canadien de chirurgie. 2002;45(4):296-302. 